\title{
Anatomic study of the distal Arcade of Superficial Layer of Supinator Muscle
}

\author{
Jenny Jacob, 'Bina Isaac¹ \\ ${ }^{1}$ Department of Anatomy, Christian Medical College, Vellore- 632002, Tamil Nadu, India
}

Disclose and conflicts of interest: none to be declared by all authors

\begin{abstract}
Introduction: entrapment of the posterior interosseous nerve can occur due to different anatomic structures, the distal arcade of the superficial layer of the supinator muscle being one of them.

Materials and Methods: An anatomic dissection of 40 upper extremities was conducted and the distances of the distal arcade and the posterior interosseous nerve from adjacent landmarks were determined.

Results: a muscular distal arcade was the most common type seen (42.5\%). The mean, standard deviation and range were calculated for each of the measurements. The comparison of the parameters between sides was done using paired t-test. Distances between the distal arcade and the humeroradial and transepicondylar lines were $90.27 \mathrm{~mm}$ and $105.62 \mathrm{~mm}$ respectively. The distance from the lateral epicondyle and the entrance and exit of the posterior interosseous nerve from supinator was $61.47 \mathrm{~mm}$ and $85.60 \mathrm{~mm}$ respectively. The distance between the proximal and distal arcades showed statistically significant difference $(p<0.041)$.

Conclusion: a knowledge of the anatomic findings of the distal arcade of the superficial layer of the supinator and the localization of the posterior interosseous nerve are important in the surgical management of posterior interosseous nerve entrapment.
\end{abstract}

Keywords: Distal arcade of supinator; Posterior interosseous nerve; Entrapment neuropathy

\section{Introduction}

The supinator muscle surrounds the proximal third of the radius. It consists of superficial and deep parts. Both the parts arise together from the lateral epicondyle, the radial collateral ligament, the annular ligament, the supinator crest of ulna and an aponeurosis that covers the muscle. The motor branch of the radial nerve or posterior interosseous nerve (PIN) is the deep terminal branch of the radial nerve. It arises anterior to the elbow joint at the level of the lateral epicondyle of the humerus and reaches the back of the forearm by passing around the lateral aspect of the radius between the two heads of supinator. It leaves the distal arcade of the supinator muscle and travels along the interosseous membrane, supplying the forearm extensor muscles. ${ }^{1}$

The posterior interosseous nerve syndrome (PIN syndrome) is a compressive neuropathy of the posterior interosseous nerve which affects the nerve supply of the forearm extensor muscles. The pain in the PIN syndrome is insidious in onset and is felt just distal to the lateral epicondyle. There is weakness of wrist and finger extension. The pain is exacerbated by repetitive acts of pronation.

The most frequent site of entrapment of PIN is found to be at the proximal arcade of the superficial layer of supinator muscle or arcade of Frohse. ${ }^{2-4}$ Another site that can cause compression is at the distal arcade of the superficial layer of supinator muscle. The exit of
PIN from the supinator was identified as a point of entrapment by Spinner (1978). The proximal fibrous edge of the extensor carpi radialis brevis (ECRB), the leash of Henry, and ganglions are other structures that can cause compression of PIN. ${ }^{5-7}$

The aim of the current study is to make a detailed anatomic description of the distal arcade of the supinator muscle and its relation with the posterior interosseous nerve.

\section{Materials and Methods}

The present study was conducted on 40 upper limbs belonging to 20 cadavers (14 males and 6 females). The age of the cadavers ranged from 40 to 90 years. All the upper limbs were scar free and had no signs of trauma or deformities. Ethical clearance was obtained from the institutional ethical committee to conduct this study.

The limbs were maintained in a midprone position during dissection. The palpable bony landmarks like the lateral and medial epicondyles, head of the radius, radial styloid process, and ulnar styloid process were identified. A longitudinal incision was made from $5 \mathrm{~cm}$ above the cubital fossa till the wrist and the fasciocutaneous flaps were reflected. The proximal and distal arcades of the superficial layer of supinator muscle were exposed. The radial nerve was identified between the brachioradialis muscle and the brachialis muscle and the division of the nerve into superficial 
branch and the posterior interosseous nerve were dissected. The lateral epicondyle, points of entry and exit of PIN from the supinator were marked using pins. The distances were measured using a measuring tape. The transepicondylar line was determined in the following manner - the lateral and medial epicondyles were palpated, and pins placed on these bony points. A white thread was used to measure the distance between these two points and the midpoint was determined. In a similar manner, the midpoint of the humeroradial joint line was determined.

The following variables were examined and analysed:

1) Nature of the distal arcade of superficial layer of supinator muscle (in males and females)

2) Distance between tip of lateral epicondyle and proximal arcade (arcade of Frohse) of superficial layer of supinator muscle

3) Distance between proximal and distal arcades of superficial layer of supinator muscle

4) Distance between humeroradial joint line and distal arcade of superficial layer of supinator muscle

5) Distance between transepicondylar line and distal arcade of superficial layer of supinator muscle

6) Distance between lateral epicondyle and entrance of PIN at arcade of Frohse (Fig. 1)

7) Distance between lateral epicondyle and exit of PIN from supinator (Fig. 1)

The data was analysed using SPSS (version 16.0). The measurements made were compared between the side of the specimen using paired t-test. A p value $<0.05$ was considered to be significant.

\section{Results}

Forty forearms and elbows were dissected. The types of distal arcade observed are shown in table 1. The nature of the distal arcade of superficial layer of supinator muscle that was most commonly seen was the muscular type (42.5\%) (Fig.2a), followed by the musculotendinous (Fig. 2b) and tendinous types (Fig. 2c). The membranous type was not found in the present study. The distances of the distal arcade and PIN from adjacent bony landmarks are shown in table 2 .
The distance between the proximal and distal arcades of the superficial layer of supinator muscle of the right and left sides showed statistically significant difference $(\mathrm{p}<0.041)$.

Table 1. Nature of distal arcade of superficial layer of supinator muscle

\begin{tabular}{l|l|l|l}
\hline $\begin{array}{c}\text { Nature of distal } \\
\text { arcade }\end{array}$ & $\begin{array}{c}\text { Total } \\
\mathbf{n}(\%)\end{array}$ & $\begin{array}{c}\text { Males } \\
\mathbf{n ( \% )}\end{array}$ & $\begin{array}{c}\text { Females } \\
\mathbf{n ( \% )}\end{array}$ \\
\hline Tendinous & $8(20 \%)$ & $4(14.2 \%)$ & $4(33.3 \%)$ \\
\hline Musculotendinous & $15(37.5 \%)$ & $11(39.2 \%)$ & $4(33.3 \%)$ \\
\hline Muscular & $17(42.5 \%)$ & $13(46.4 \%)$ & $4(33.3 \%)$ \\
\hline
\end{tabular}

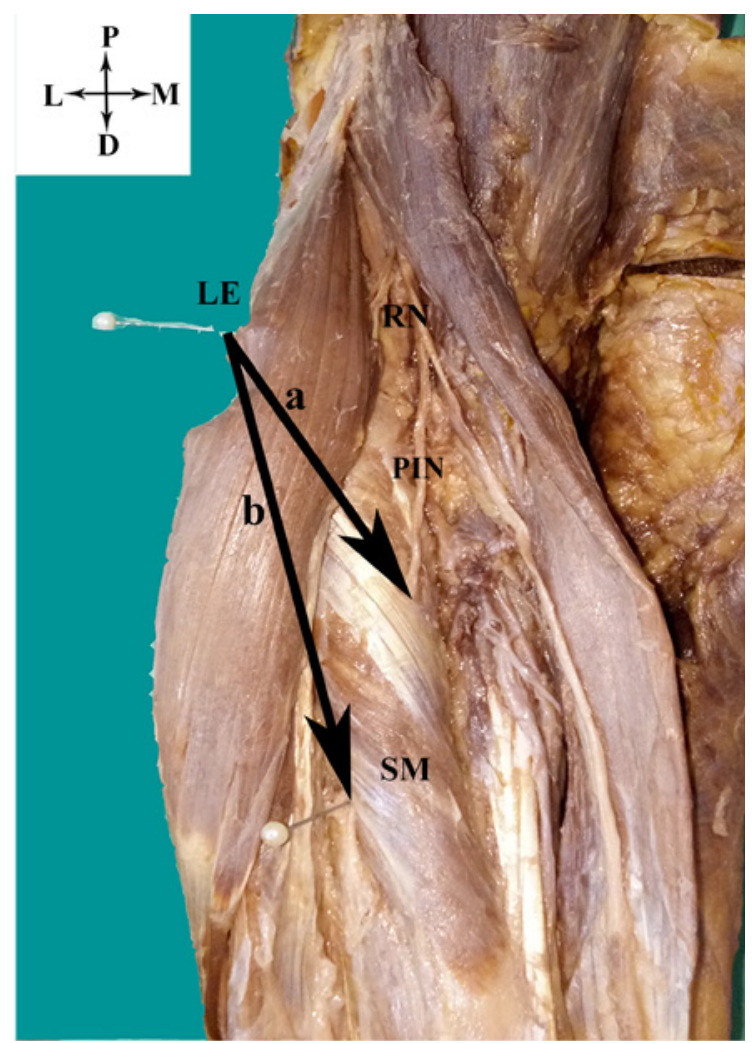

Figure 1. Lateral epicondyle and posterior interosseous nerve. a - distance between lateral epicondyle and entry of PIN at arcade of Frohse. b - distance between lateral epicondyle and exit of PIN at distal arcade of superficial layer of supinator.

LE, lateral epicondyle; RN, radial nerve; PIN, posterior interosseous nerve; SM, supinator muscle.

Table 2. Distances from the distal arcade and posterior interosseous nerve to important anatomical landmarks

\begin{tabular}{|l|c|c|}
\hline \multicolumn{1}{|c|}{ Parameter } & Mean \pm SD (mm) & Range (mm) \\
\hline $\begin{array}{l}\text { Distance between tip of lateral epicondyle and proximal arcade of superficial layer of } \\
\text { supinator muscle }\end{array}$ & $59.60 \pm 8.49$ & $50-74$ \\
\hline Distance between proximal and distal arcades of superficial layer of supinator muscle & $52.45 \pm 13.96$ & $30-80$ \\
\hline $\begin{array}{l}\text { Distance between humeroradial joint line and distal arcade of superficial layer of } \\
\text { supinator muscle }\end{array}$ & $90.27 \pm 10.17$ & $71-108$ \\
\hline $\begin{array}{l}\text { Distance between transepicondylar line and distal arcade of superficial layer of supinator } \\
\text { muscle }\end{array}$ & $105.62 \pm 10.80$ \\
\hline $\begin{array}{l}\text { Distance between lateral epicondyle and entry of PIN into supinator at the proximal } \\
\text { arcade }\end{array}$ & $82-122$ \\
\hline Distance between lateral epicondyle and exit of PIN from supinator & $85.60 \pm 9.66$ & $64-95$ \\
\hline
\end{tabular}



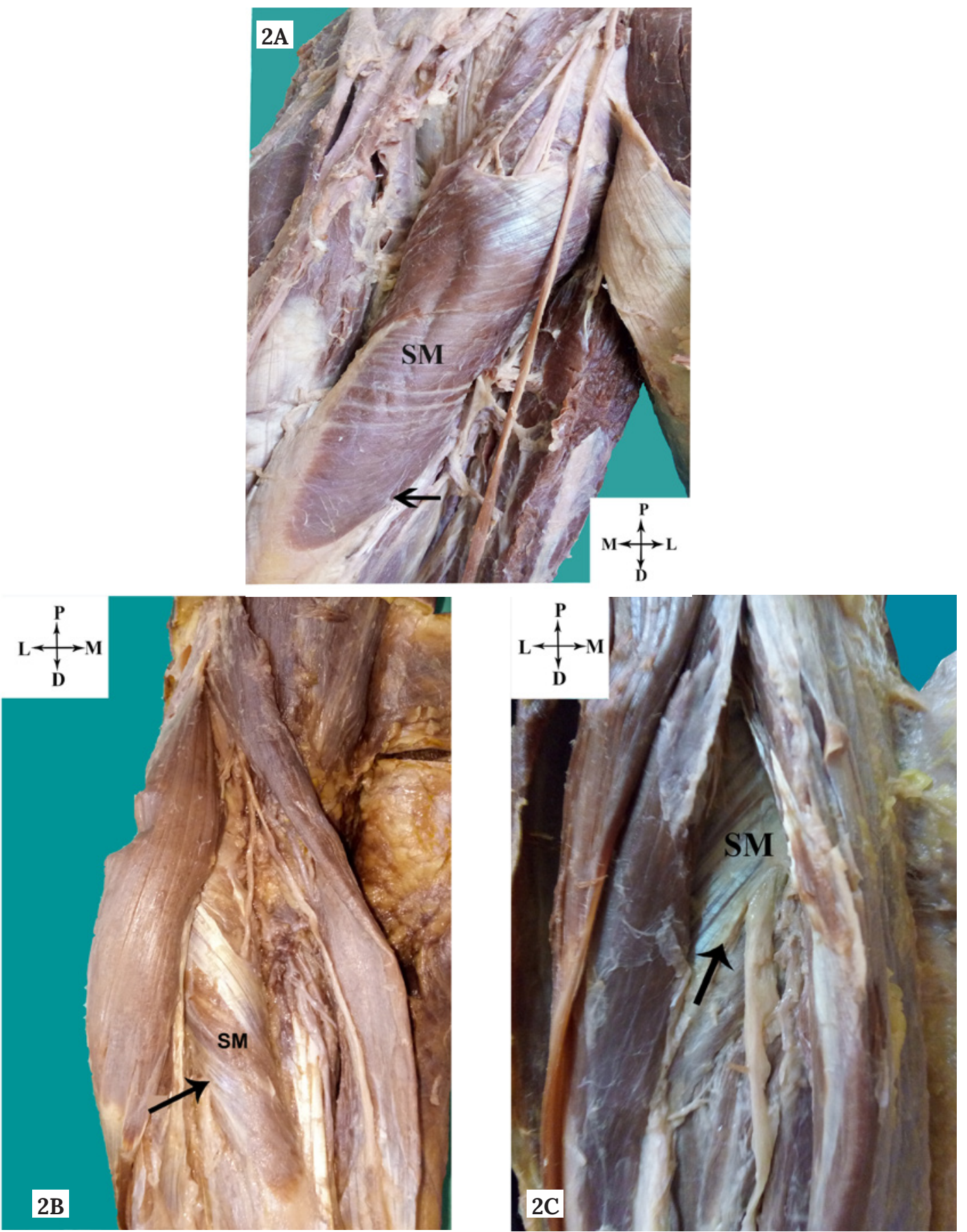

Figure 2. Types of distal arcade of superficial layer of supinator muscle (Arrow). (A) Muscular type (B) Musculotendinous type (C) Tendinous type SM, supinator muscle.

\section{Discussion}

The supinator muscle has a close relationship with the motor branch of the radial nerve or the posterior interosseous nerve (PIN). The PIN travels in the narrow space between the superficial and deep layers of the supinator and while doing so, can become compressed leading to a dull aching pain on the lateral aspect of the elbow and proximal aspect of the lateral forearm. ${ }^{8}$ Various compressive anatomical elements have been described; the most known of which is the proximal and distal arcades of the superficial layer of the supinator muscle, the medial aspect of the ECRB muscle, the vascular arcade of the radial recurrent artery and its branches, and a capsular-tendon-aponeurosis group located on the anterior aspect of both the humeroradial joint and the radial head. ${ }^{9-11}$ Neuromas, ${ }^{12}$ schwannomas ${ }^{13}$ traumatic aneurysms of the posterior interosseous artery, ${ }^{8}$ neurofibromas ${ }^{14}$ ganglion cysts,${ }^{15}$ and myxomas ${ }^{16}$ are other structures that have been reported as causes of paralysis of the PIN. Trauma may cause paralysis of this nerve; however, many cases of PIN entrapment have no history of antecedent trauma. ${ }^{17}$

The posterior interosseous nerve entrapment syndrome, is common in tennis players. ${ }^{18}$ It is mainly 
a motor syndrome characterized by a reduction or loss of extension of all digits and atrophy of the posterior forearm muscles with the exclusion of the brachioradialis and extensor carpi radialis longus. Since the extensor carpi radialis longus muscle is usually innervated by the radial nerve trunk, there is usually no wrist drop. When wrist extension is examined, it deviates radially because of contraction of the extensor carpi radialis longus muscle.

The proximal edge of the superficial layer of the supinator muscle (arcade of Frohse) is the one most often implicated as the causative factor for the PIN syndrome. ${ }^{2,11}$ Repetitive movements of pronation and supination can promote compression of the PIN under the arcade of Frohse..$^{10,13}$ It was observed that fibrous or tendinous arcades only compress the PIN. ${ }^{19,20}$ In 1908, Frohse and Frankel, first described the arcade of Frohse as a normal anatomical tendinous structure. ${ }^{2}$ Spinner suggested that the most proximal part of the superficial layer of the supinator muscle was always muscular in the newborn full-term foetuses and it became a semicircular structure in adults due to the repeated rotatory movements of pronation and supination of the forearm. ${ }^{7}$ Tatar et al. reported the same findings in their study on 40 fetuses' forearms. ${ }^{21}$

The distal arcade of the superficial layer of the supinator muscle is another structure which can cause compression of the PIN. Sponseller and Engber (1983) first described the distal arcade as a potential compressive element for the PIN as it exits the supinator. ${ }^{22}$ Riffaud et al. ${ }^{11}$ found in their study, the majority of distal arcades possessed a muscular nature whereas, the nature was tendinous in the studies by Prasartritha et al. ${ }^{24}$ Konjengbam and Elangbam ${ }^{10}$ and Berton et al. ${ }^{23}$ (Table 3). The findings in the present study, regarding the nature of the distal arcade, are in accordance with those of Riffaud et al. ${ }^{11}$ Repetitive pronation and supination can aggravate the compression of PIN, as it leaves the supinator muscle under the distal arcade. In males, the muscular type of distal arcade was the commonest type seen, in keeping with their heavy body build.

The relationship of the PIN to adjacent bony landmarks should be kept in mind by surgeons, while treating PIN entrapment. ${ }^{9,25}$ The lateral epicondyle is a useful anatomical reference landmark, that can be used to locate the arcades of the supinator muscle. In the present study, the distance between the arcade of Frohse and the lateral epicondyle was $59.60 \mathrm{~mm}$. This is almost in line with the results of Werner ${ }^{26}(47$ $\mathrm{mm})$, Ozturk et al. $^{3}(46.2 \mathrm{~mm})$, Papadopoulos et al. ${ }^{27}$ $(49.1 \mathrm{~mm})$ and Artico et al. ${ }^{9}(53 \mathrm{~mm})$. In the present study, the distance between the proximal and distal arcades was $52.45 \mathrm{~mm}$. This is almost similar to the findings of Berton et al. ${ }^{23}(41.4 \mathrm{~mm})$ and Konjengham and Elangbam ${ }^{10}(42 \mathrm{~mm})$, but is different from those of Artico et al. ${ }^{9}(31 \mathrm{~mm})$.

The knowledge of the distances of the entrance and exit of PIN from supinator is important in the surgical treatment of the posterior interosseous nerve entrapment. In the present study, the distances from the lateral epicondyle and the entrance of PIN at the arcade of Frohse and exit of PIN at the distal arcade was found to be $61.47 \mathrm{~mm}$ and $85.60 \mathrm{~mm}$ respectively. These findings are in accordance with the findings in the study by Tubbs et al. ${ }^{28}$ where the mean distance from the lateral epicondyle and the entrance of PIN at the arcade of Frohse was found to be $60 \mathrm{~mm}$ (45- 75 $\mathrm{mm}$ ) and the mean distance from the lateral epicondyle to the exit of PIN at the distal arcade was found to be $120 \mathrm{~mm}(100-150 \mathrm{~mm})$. Other anatomical landmarks that can be used to localise PIN are the humeroradial joint line and the transepicondylar line.

Surgical therapy for an entrapped PIN is indicated after 3 months of conservative therapy if functional recovery is absent or if symptoms worsen. Operative release of the PIN is generally successful, ${ }^{29}$ providing relief to the patient. The findings in the present study will aid the neurosurgeon in decompression of the PIN with least amount of surgical morbidity.

The distal arcade though known to be a zone of compression for the posterior interosseous nerve has not been well described. Our observation of a muscular distal arcade in most of the specimens is valuable as chronic repetition of pronation-supination movements can cause modifications of this muscular

Table 3. Nature of the distal arcade of the superficial layer of supinator muscle in different studies.

\begin{tabular}{|c|c|c|c|c|c|}
\hline Study & $\mathbf{n}$ & $\begin{array}{l}\text { Tendinous } \\
(\%)\end{array}$ & $\begin{array}{c}\text { Musculo-Tendinous } \\
(\%)\end{array}$ & $\begin{array}{l}\text { Muscular } \\
(\%)\end{array}$ & $\begin{array}{c}\text { Membranous } \\
\text { (\%) }\end{array}$ \\
\hline Prasartritha et al. ${ }^{24}$ & 60 & 65 & 0 & 0 & 35 \\
\hline Riffaud et al. ${ }^{11}$ & 25 & 4 & 8 & 88 & 0 \\
\hline Konjengbam and Elangbam ${ }^{10}$ & 46 & 65 & 11 & 22 & 2 \\
\hline Ozturk et al. ${ }^{3}$ & 55 & 87 & 0 & 0 & 13 \\
\hline Berton et al. ${ }^{23}$ & 30 & 37 & 33 & 27 & 3 \\
\hline Present study & 40 & 20 & 37.5 & 42.5 & 0 \\
\hline
\end{tabular}


structure, leading to real pathology. The localization of the PIN in relation to lateral epicondyle should help at the time of PIN neurolysis. Knowledge of the position of the distal arcade in relation to the humeroradial and transepicondylar lines may be helpful for the surgeon whose target is to decompress the PIN in the surgical management of lateral elbow pain.

The limitation of the present study was that it was done on hard fixed formalin embalmed upper extremities. In the actual surgical setting, the tissues are supple and soft. Further studies in fresh cadaveric specimens are required, so that anatomic data derived from such studies can be applied to the clinical setting during the treatment of posterior interosseous nerve entrapment.

\section{Conclusion}

In conclusion, we can say that these anatomic findings of the distal arcade of superficial layer of supinator muscle must be considered in the pathophysiology of the posterior interosseous nerve syndrome. A knowledge of the distances of the distal arcade of the superficial layer of supinator from certain anatomic landmarks is an essential prerequisite to the surgical management of the posterior interosseous nerve neuropathy. The localization of the entrance and exit of the PIN in relation to a reference point like the lateral epicondyle will help to prevent iatrogenic injuries during the treatment of posterior interosseous nerve entrapment.

\section{References}

1. Standring S. Gray's anatomy-anatomical basis of clinical practice. 41st ed. Philadelphia: Elsevier; 2016: 855

2. Frohse F, Frankel M. Die Muskeln des menschlichen Armes. Fischer Jena; 1908: 164-9

3. Ozturk A, Kutlu C, Taskara N, Kale AC, Bayraktar B, Cecen A. Anatomic and morphometric study of the arcade of Frohse in cadavers. Surg Radiol Anat 2005;27:171-5

4. Clavert P, Lutz JC, Adam P, Wolfram-Gabel R, Liverneaux P, Kahn JL. Frohse's arcade is not the exclusive compression site of the radial nerve in its tunnel. Orthop Traumatol Surg Res 2009;95:114-8

5 . Capener N. The vulnerability of the posterior interosseous nerve of the forearm. A case report and an anatomical study. J Bone Joint Surg $\mathrm{Br}$ 1966;48(4):770-3

6. Ducic I, Felder JM, Quadri HS. Common nerve decompressions of the upper extremity. Ann Plast Surg 2012;68:606-9

7. Spinner M. The arcade of Frohse and its relationship to posterior interosseous nerve paralysis. J Bone Joint Surg Br 1968;50(4):809-12 8. Dharapak C, Nimberg GA. Posterior interosseous nerve compression. Report of a case caused by traumatic aneurysm. Clin Orthop 1974;101:225-228

9. Artico M, Telera S, Tiengo C, et al. Surgical anatomy of the radial nerve at the elbow. Surg Radiol Anat SRA 2009 Feb;31(2):101-6

10. Konjengbam $M$, Elangbam J. Radial nerve in the radial tunnel: anatomic sites of entrapment neuropathy. Clin Anat 2004; 17(1):21-25 11. Riffaud L, Morandi X, Godey B, et al. Anatomic bases for the compression and neurolysis of the deep branch of the radial nerve in the radial tunnel. Surg Radiol Anat 1999; 21(4):229-233

12. Loh YC, Stanley JK, Jari S, Trail IA. Neuroma of the distal posterior interosseous nerve. A cause of iatrogenic wrist pain. J Bone Joint Surg Br 1998;80:629-630

13. Cravens G, Kline DG. Posterior interosseous nerve palsies. Neurosurgery 1990;27:397-402

14. Lallemand RC, Weller RO. Intraneural neurofibromas involving the posterior interosseous nerve. J Neurol Neurosurg Psychiatry 1973;36:991-996

15. Bowen TL, Stone KH. Posterior interosseous nerve paralysis caused by a ganglion at the elbow. J Bone Joint Surg Br 1966;48: 774-776

16. Valer A, Carrera L, Ramirez G. Myxoma causing paralysis of the posterior interosseous nerve. Acta Orthop Belg 1993; 59:423-425 17. Doyle JR. Surgical Anatomy of the Hand and Upper Extremity. Philadelphia: Lippincott Williams \& Wilkins; 2003: 461-485

18. Lorei MP, Hershman EB. Peripheral nerve injuries in athletes. Treatment and prevention. Sports Med 1993;16:130-147

19. Thomas SJ, Yakin DE, Parry BR, Lubahn JD, Erie PA. The anatomical relationship between the posterior interosseous nerve and the supinator muscle. J Hand Surg Am 2000;25(5):936-941

20. Lister GD, Belsole RB, Kleinert HE. The radial tunnel syndrome. J Hand Surg Am 1979; 4(1):52-59

21.Tatar I, Kocabiyik N, Gayretli O, Ozan H. The course and branching pattern of the deep branch of the radial nerve in relation to the supinator muscle in fetus elbow. Surg Radiol Anat 2009;31(8):591596

22. Sponseller PD, Engber WD. Double-entrapment radial tunnel syndrome. J Hand Surg Am 1983; 8(4):420-423

23. Berton C, Wavreille G, Lecomte F, Miletic B, Kim HJ, Fontaine C. The supinator muscle: anatomical bases for deep branch of the radial nerve entrapment. Surg Radiol Anat 2012;35:1024

24. Prasartritha T, Liupolvanish P, Rojanakit A. A study of the posterior interosseous nerve (PIN) and the radial tunnel in 30 Thai cadavers. J Hand Surg Am 1993; 18(1):107-112

25. Heidari N, Kraus T, Weinberg AM, Weiglein AH, Grechenig W. The risk injury to the posterior interosseous nerve in standard approaches to the proximal radius: a cadaver study. Surg Radiol Anat 2011; 33(4):353-357

26. Werner CO. Lateral elbow pain and posterior interosseous nerve entrapment. Acta Orthop Scand Suppl 1979; 174:1-62

27. Papadopoulos N, Paraschos A, Pelekis P. Anatomical observations on the arcade of Frohse and other structures related to the deep radial nerve. Anatomical interpretation of deep radial nerve entrapment neuropathy. Folia Morphol (Praha) 1989; 37(3):319-327 28. Tubbs RS, Salter EG, Wellons JC, Blount JP, Oakes WJ. Superficial surgical landmarks for identifying the posterior interosseous nerve. J Neurosurg 2006; 104:796-799

29. Ozkan M, Bacakoglu AK, Gul O, Ekin A, Magden O. Anatomic study of posterior interosseous nerve in the arcade of Frohse. J Shoulder Elbow Surg 1999; 8:617-620 